\title{
Amorphization Mitigation in Boron-Rich Boron Carbides Quantified by Raman Spectroscopy
}

\author{
Mark C. Schaefer and Richard A. Haber * \\ Department of Materials Science and Engineering, Rutgers, The State University of New Jersey, 609 Taylor Road, \\ Piscataway, NJ 08854, USA; mcs309@scarletmail.rutgers.edu \\ * Correspondence: rich.haber@rutgers.edu
}

Received: 29 May 2020; Accepted: 6 July 2020; Published: 23 July 2020

\begin{abstract}
Boron carbide is an extremely hard and lightweight material used in armor systems. Upon impact above the Hugoniot elastic limit (HEL), boron carbide loses strength and suddenly fails. Atomistic models suggest that boron-rich boron carbides could mitigate amorphization. Such samples were processed, and indentation-induced amorphous zones were created throughout the boron-rich samples of varying degrees and were mapped with Raman spectroscopy to assess changes in the amorphization intensity. Boron-rich samples with a $\mathrm{B} / \mathrm{C}$ ratio of 6.3 showed a large reduction in amorphization intensity compared to commonly used stoichiometric $B_{4} C$, in agreement with recent TEM results. Additionally, hardness trends were also noted as boron content is varied. This offers another pathway in which doping boron carbide can reduce amorphization.
\end{abstract}

Keywords: boron carbide; amorphization; Raman

\section{Introduction}

Boron carbide is an ultrahard ceramic material that has many useful applications, most notably as body armor. This is due to the material's high hardness ( $>30 \mathrm{GPa})$, coupled with its low density $\left(2.52 \mathrm{~g} / \mathrm{cm}^{3}\right)$ [1-3]. The boron carbide $\left(B_{4} C\right)$ structure is predominantly made up of $\left(B_{11} C\right)$ icosahedra, with the carbon atom residing in a polar site and the $\mathrm{CBC}$ chain connecting the icosahedra along the main diagonal of a rhombohedral unit cell $[1,2,4]$. However, boron carbide is very brittle and undergoes softening past the critical HEL point, unlike similar ceramics such as silicon carbide [5]. This loss of strength limits the material's performance in critical applications. The sudden failure of boron carbide under impact has been attributed to amorphization, the formation of nanometer-sized bands that form as a result of high stresses or impacts [6,7]. Amorphization has been observed under many various testing conditions, such as indentation [6,8-11], scratching techniques $[8,12]$, ballistic impact [7], plate impact testing [13], sufficient electric fields [14], laser shock compression [15], radiation exposure [16,17], and diamond anvil cell experiments [18].

There has been much computational work done to simulate the exact mechanism of amorphization, in addition to suggestions of how to process better performing, amorphization-resistant boron carbide. There have been several different mechanisms proposed to explain the phenomena of amorphization.

The boron carbide structure is one with many possibilities and stable polytypes [19]. Since boron atoms and carbon atoms are similar in size, they can substitute one another, leading to variation from unit cell to unit cell, and there can be many possible stable and energetically favorable structures present. Unit cells that have the same empirical formula, such as $B_{4} C$, but have a different structure are referred to as different polytypes of boron carbide [20]. Various attempts have been made to simulate the boron carbide structure in order to identify the stability of many abundant polytypes. The $\left(\mathrm{B}_{12}\right) \mathrm{CCC}$ polytype was identified as being the least stable polytype, favoring a segregation to $\left(\mathrm{B}_{12}\right)$ and graphitic carbon past a critical pressure of $6 \mathrm{GPa}$ [4]. 
Atomistic modeling also shows that many elemental dopants can alter the structure of boron carbide to improve ductility under high stresses, thus mitigating amorphization. These models start with the most energetically favorable and abundant polytype in $B_{4} C$, a $\left(B_{11} C_{p}\right)$ icosahedra with icosahedra connected by a CBC chain. An et al. claims that this polytype is believed to be the cause of amorphization and the loss of shear strength [21]. They suggest that the possible mechanism for amorphization is as follows: under high stresses and pure shear, the chain in the boron carbide structure will bend, causing the $C$ atom at the center of the chain to interact with the nearby icosahedra, such that a permanent bond forms between the C-chain atom and the B-icosahedral atom, causing the structure to collapse [21].

An et al.'s work proposes many novel boron carbide-doped structures that do not amorphize under strains or shear, including silicon, phosphorous, or even oxygen doping. Most of these structures show the new dopant being introduced into the chain structure, which can create a more stable structure that will not interact with the icosahedra under different loading regimes [22,23]. The addition of boron to the boron carbide matrix could also mitigate amorphization, as it would prevent chain-icosahedra interactions and bonding under loading [21].

A newer model from Awasthi et al. [24] surmises that amorphization is caused by defects in boron carbide. Defects act as stress concentrators, which in turn lowers the local melting point in the material. Thus, melting occurs as a result of localized increases in temperature and pressure, which then quenches to form amorphous bands that are seen experimentally. This idea is similar to recent TEM work that surmises that amorphization from ion radiation begins as point defects that grow and propagate into amorphous bands [17].

Density functional theory (DFT) calculations showing several boron carbide phases under high temperatures and pressures determines that stable polytypes of $\left(B_{11} C_{p}\right) C B C$ are made boron-rich by replacing one third of the $\mathrm{CBC}$ chain with one of two possible modified block structures [25].

While past work studying boron-rich boron carbides has been done, little attention has been paid to experimental observations of amorphization in these materials. Aselage states that a boron carbide with additional boron will result in the expansion of the unit cell [26]. Furthermore, Tallant determined that several polytype structures can be present in experimental boron carbide materials, such as $\left(B_{11} C\right)$ and $\left(\mathrm{B}_{12}\right)$ icosahedra, and $\mathrm{CBC}$ and $\mathrm{CCC}$ chains [3]. When going to the boron-rich end of the $\mathrm{B}-\mathrm{C}$ phase diagram, boron can substitute out carbon atoms in either the icosahedra or chain, going from $\left(B_{11} C\right)$ to $\left(\mathrm{B}_{12}\right)$ icosahedra, or a CBC chain to a CCC chain, respectively, for each possible case [3]. Yakel also proposed a four-atom planar boron unit to connect icosahedra in extreme boron-rich boron carbides, but this has not been experimentally verified [27]. As far as the icosahedra and chain substitutions, there has been intense debate as to which happens preferentially. It is theorized that one substitution preferentially occurs to transform $\mathrm{B}_{4} \mathrm{C}$ to $\mathrm{B}_{13} \mathrm{C}_{2}$, then the other substitution occurs when the boron limit is approached from $B_{13} C_{2}$. Some believe that the initial substitution occurs in the chain [28], while Xie et al. claims that the initial boron atom substitutes the carbon atom in the icosahedra [29] and that the icosahedra is more susceptible to collapse in comparison to the chain [30].

The goal of this work is to determine if increasing the $\mathrm{B} / \mathrm{C}$ ratio in boron carbide shows a reduction in the amorphization intensity, as quantified by Raman spectroscopy, in order to further support recent TEM observations suggesting this in boron-rich boron carbides [31]. This work is also advantageous because boron-rich boron carbides can also exhibit good stability under high pressure, as determined in newly published DFT work, which is beneficial for defense applications [25].

\section{Materials \& Methods}

Boron carbide and boron-rich boron carbide were prepared at Rutgers University. This was done by sintering powder mixes of Rutgers-made boron carbide powder, synthesized using the rapid carbo-thermal reduction (RCR) process along with high purity amorphous boron powder. Samples had undergone sintering hold times of up to $10 \mathrm{~min}$, with temperatures of up to $1900{ }^{\circ} \mathrm{C}$. Samples ranging from $\mathrm{B}_{4} \mathrm{C}$ through $\mathrm{B}_{7} \mathrm{C}$ were synthesized, all having at least $98 \%$ theoretical density [32]. 
The extensive characterization of the samples was conducted, and sample stoichiometries were denoted by their experimentally confirmed $\mathrm{B} / \mathrm{C}$ ratio rather than their pre-sintered nomenclature. All analyses confirmed that all samples were entirely and fully reacted. Samples were ground down and polished to $0.05 \mu \mathrm{m}$ diamond pads. The cores of the samples produced were considered for this study due to carbon from dies reacting with the powders at the edges of the dies, resulting in stoichiometric $\mathrm{B}_{4} \mathrm{C}$ on the outer edges of samples; the most boron-rich regions of the samples were the cores due to being free of carbon contamination from graphite dies. Boron nitride spacers and coatings were also used to mitigate carbon diffusion from the die set. Raman spectroscopy, X-ray diffraction (XRD), and chemical analysis were used to fully understand the nature of the samples produced. As expected, there was a downshift in the Raman and XRD peaks for the more boron-rich samples, corresponding to a lattice expansion from boron atoms replacing carbon atoms in the lattice. Additionally, refinements of X-ray data gave lattice parameters to the samples. Chemical analysis of the samples included titrations to determine the total boron content, as well as combustion reaction analyzers to determine how much total carbon and oxygen was in the final samples [32].

For this study, $500 \mathrm{~g}$ Vickers indentation was used as a way to induce amorphization in boron carbide and interrogate hardness. The larger area from the Vickers indents allowed amorphization to be probed in greater detail compared to nanoindentation.

Raman spectroscopy was used to analyze the surface of the indents for amorphization. A Renishaw InVia Microspectrometer was used with a $633 \mathrm{~nm}$ laser. Spectra were taken for $10 \mathrm{~s}$ using a $40 \mathrm{~mW}$ laser, and any heating effects should be minimal for a bulk sample. Heating of boron carbide from a laser can result in oxidation of the sample, creating boric acid and graphite [33], but no such reactions were discovered in these measurements. The range of $200-2000 \mathrm{~cm}^{-1}$ was probed to observe amorphous peaks for quantification. Map sizes were approximately $20 \times 20 \mu \mathrm{m}$, with a scanning step size of $0.5 \mu \mathrm{m}$. Raman spectroscopy is a quick and non-destructive method for probing the "amorphous phase" of boron carbide, owing to the unique Raman spectra of the amorphized region [6].

Samples with 13.7, 17.4, and 19.9 at.\% C were considered in this study. The indentation regions were mapped in their entirety, along with some of the immediate surrounding pristine surface. Raman mapping takes thousands of spectra in and around each indent, mapping the crystalline and amorphous zones of the area. For each sample, 10 separate indents were mapped, utilizing indents that were free of any defects, porosity, or pullouts as a result of indentation or polishing. The entire indent was mapped, since the amorphization intensity is not necessarily most intense at the apex of the indent [34], so this total mapping accounts for any variation in maximum intensity by accounting for all amorphous behavior as a result of an indent.

Raman spectra quantification is the summation of each spectrum's contribution from an indent-map. A spectrum is quantified as the peak area of the $1800 \mathrm{~cm}^{-1}$ amorphous peak, normalized to the crystalline contributions from $900-1100 \mathrm{~cm}^{-1}$ range, similar to other work done on evaluating silicon-doped boron carbides [35,36].

Only the $1800 \mathrm{~cm}^{-1}$ peak was used because it is solely attributed to amorphous boron carbide in the literature, so utilizing this peak to represent amorphization meant that a reduction of amorphization could be determined. The amorphous peaks at 1300 and $1500 \mathrm{~cm}^{-1}$ overlapped with the D- and G-bands of graphitic carbon, and this could be the result of contributions from those graphitic features, which are inherently smaller in boron-rich samples.

\section{Results}

Looking at the crystalline Raman spectra of the samples being studied in Figure 1, there are several features that differ as the $\mathrm{B} / \mathrm{C}$ ratio is modified. The $\mathrm{B}_{4} \mathrm{C}$ sample spectra are in alignment with what has been clearly noted in the literature $[1,3,37]$. However, new peaks at 180 and $375 \mathrm{~cm}^{-1}$ are observed as slight shoulders forming from the 270 and $320 \mathrm{~cm}^{-1}$ peaks in the boron-rich samples around the $B_{13} C_{2}\left(13.3\right.$ at. $\%$ C) configuration. The $1080 \mathrm{~cm}^{-1}$ icosahedra breathing mode (IBM) shows a consistent downshifting as boron content is increased, which is where the expected lattice expansion 
for boron-rich samples should be seen. This is indicative of boron-doping initially substituting within the icosahedra. Additionally, some small contributions from peaks between 900 and $1030 \mathrm{~cm}^{-1}$ become more prominent in the most boron-rich sample, along with a small shoulder on the right side of the IBM peak. All other major peaks, 280, 320,480, and $530 \mathrm{~cm}^{-1}$, remain fairly consistent and unchanged throughout the stoichiometry range studied here.

Based on the Raman spectra from the samples investigated, it is determined that the initial boron atom substitutes into the icosahedra in $B_{4} C$, modifying the icosahedra from $\left(B_{11} C\right)$ to $\left(B_{12}\right)$. This is seen in the Raman spectra to varying extent for all levels of the boron-doped samples and is assumed for this study, as supported by previous work by Xie et al. [29,30]. Thus, boron-rich boron carbide samples are presumably comprised of $\left(B_{12}\right) C B C$ units, which address mitigating amorphization from either the $\left(B_{11} C\right) C B C$ or $\left(B_{12}\right) C C C$ polytypes, as suggested by multiple models [4,21].

Maps from the three boron carbide samples were analyzed and quantified. Figure 2 shows color-intensity maps, denoting intensity from the $1800 \mathrm{~cm}^{-1}$ peak. Visually, a reduction in amorphization intensity can be seen in the two boron-rich samples.

All individual spectra were normalized before any color intensity maps were generated or spectra were quantified.



Figure 1. Raman spectra of pristine boron carbide samples, $B_{4} C, B_{4.7} C$, and $B_{6.3} C$, used in this study. In virgin surface measurements, no prominent peaks are seen past $1200 \mathrm{~cm}^{-1}$, where amorphous peaks present themselves.

All maps for all sample stoichiometries show that amorphization is always contained within the contact area of the indenter; the amorphization-related signal does not occur in the materials beyond the bounds of the indented region. All damage is in the subsurface of the samples beneath the indents Amorphization does not extend or propagate laterally in the material. This means that any variations in map size will not add additional amorphous signal from the surrounding crystalline region, regardless of how much or little is probed, as long as the entirety of the indent is within the limits of the map. 


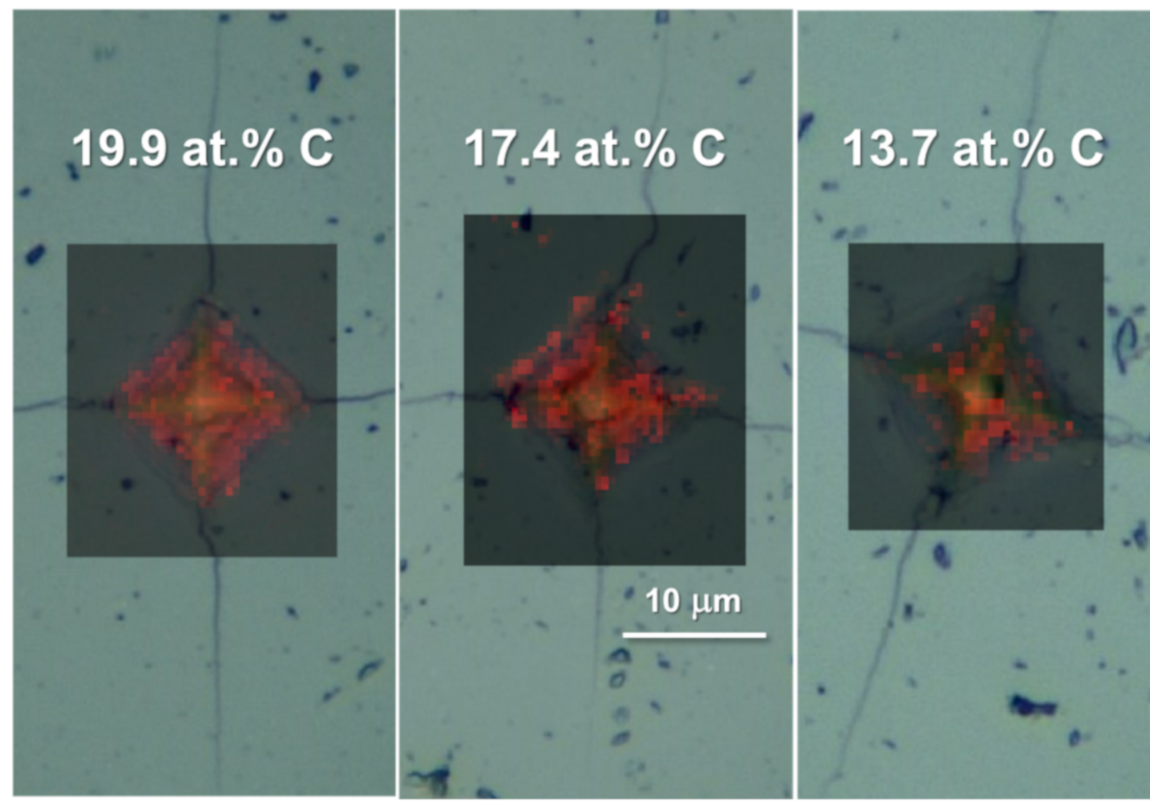

Figure 2. Pseudo-color intensity maps generated by an area-map of Raman spectroscopy with a $633 \mathrm{~nm}$ laser.

Each pixel in the darkened mapped images seen in Figure 2 represents a site where a spectrum was taken, and each spectrum has a value associated with it, which is the area of the $1800 \mathrm{~cm}^{-1}$ amorphous peak normalized to the crystalline peaks from 900 to $1100 \mathrm{~cm}^{-1}$. Each spectrum from a given map was then summed, giving the total extent of amorphization intensity from that indent. Again, 8-10 pristine indents were probed and quantified, yielding the average for a given stoichiometry. Figure 3 shows representative Raman spectra from within a boron carbide and boron-rich boron carbide's indented area. The highlighted areas in red designate the amorphous peaks, and a clear reduction in intensity can be discerned.

Given that all values were normalized to $B_{4} C$, the average of the total amorphization seen from an indent in that sample was set at one. Relative to standard boron carbide, $\mathrm{B}_{4.7} \mathrm{C}$ had a total value of 0.45 , and $\mathrm{B}_{6.3} \mathrm{C}$ had a value of 0.30 for the total amorphization intensity, giving a $55 \%$ and $70 \%$ reduction in amorphization intensity for $\mathrm{B}_{4.3} \mathrm{C}$ and $\mathrm{B}_{6.3} \mathrm{C}$, respectively. This result is shown graphically in Figure 4.

These findings of amorphization mitigation are consistent with the modeling, since the any $\mathrm{B}_{4} \mathrm{C}$ polytype susceptible to failure will be replaced by a more ductile, although less hard, $\mathrm{B}_{13} \mathrm{C}_{2}$ polytype. Even considering an experimental sample can be a blend of polytypes, and with different stoichiometries, there should be less $\mathrm{B}_{4} \mathrm{C}$ unit cells present in boron-rich boron carbides, instead favoring a boron-rich polytype such as $\left(\mathrm{B}_{12}\right) \mathrm{CBC}$. If this is the case, the boron-enriched icosahedra will not lend its carbon atom to interactions with the chain under bending and strain. Conversely, although less likely, if a boron-rich polytype is $\left(B_{11} C\right) C B B$, then the chain would be less prone to chain-icosahedra interactions because a CBB chain would be asymmetric and strained.

Additionally, $\mathrm{B}_{4} \mathrm{C}$ had a hardness of $34.6 \mathrm{GPa}(1.4 \mathrm{GPa})$, and $\mathrm{B}_{4.7} \mathrm{C}$ was calculated as $31.9 \mathrm{GPa}$ (2 GPa), with $\mathrm{B}_{6.3} \mathrm{C}$ at $32.7 \mathrm{GPa}(1.5 \mathrm{GPa})$. Standard errors are given in parentheses and, although large, a small possible drop in hardness is noted for the boron-rich sample.

Yang et al. [35] uses a similar amorphization-quantification method that accounts for size differences between indents in samples of differing compositions. Although amorphization is seen in the indented region of a sample, because samples with varying composition have different hardness values, these indented areas will differ. Thus, the amorphized regions created by the indents will vary in size. Thus, while it may seem critical to account for indent size variation, this does not change the result that amorphization intensity is reduced in boron-rich samples. Since boron-rich samples tend to have lower 
hardness values, their indented areas are larger, so a reduction in amorphization intensity is seen from a larger amorphized area. If size differences were accounted for, a further reduction would be seen in the boron-rich samples.

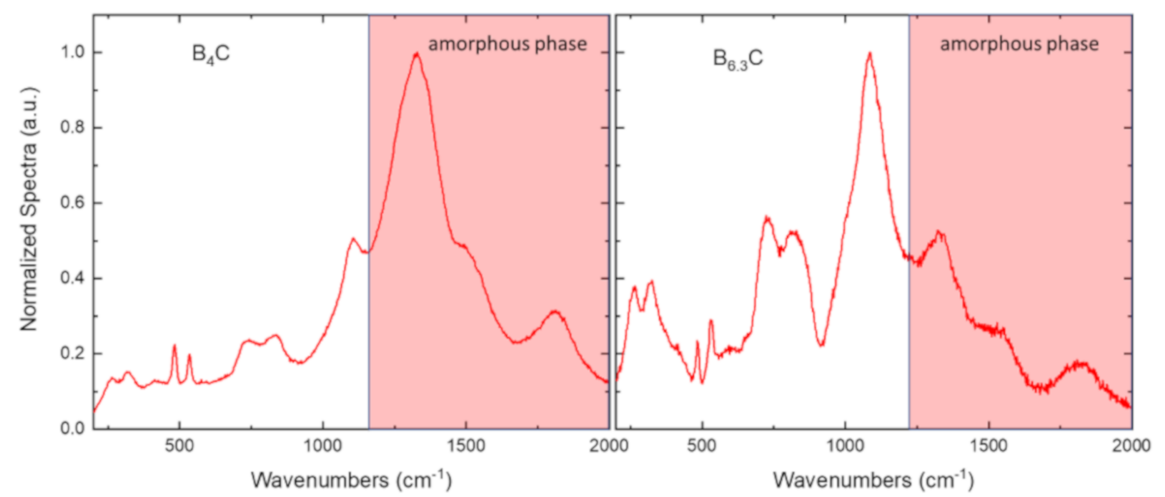

Figure 3. Comparison of amorphized Raman spectra of $\mathrm{B}_{4} \mathrm{C}$ (left) and $\mathrm{B}_{6.3} \mathrm{C}$ (right). Amorphous peaks (greater than $1200 \mathrm{~cm}^{-1}$ ) are highlighted in red.

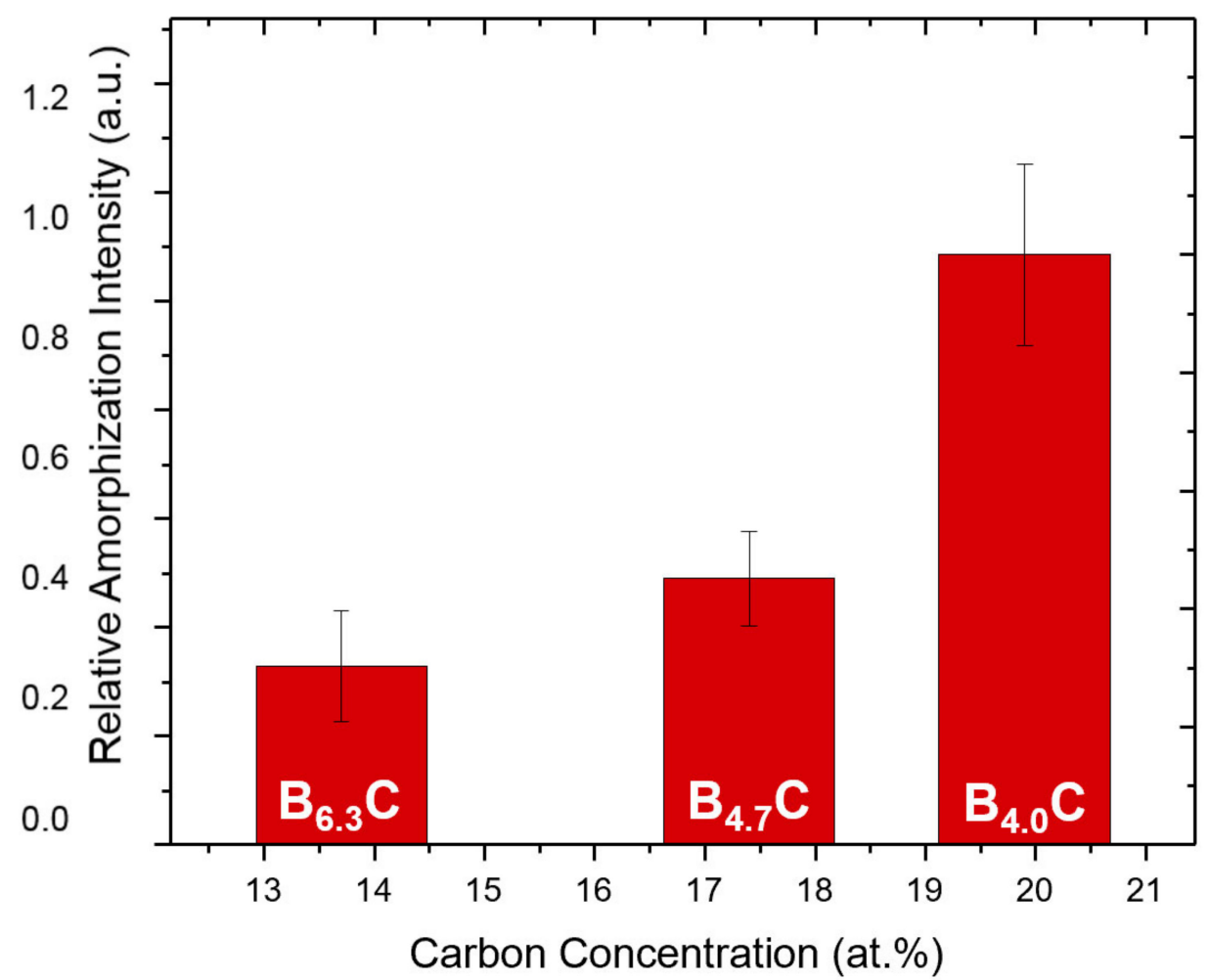

Figure 4. Graphic results of amorphization intensity mitigation for boron-rich boron carbides.

While there is agreement between this and recent TEM results [31] indicating a reduction in amorphization in boron-rich boron carbides, Raman showed a 70\% reduction, while TEM results determined a 30\% reduction. This discrepancy does not diminish the results from either method, nor does it diminish their significance. Differences in total reduction between the two methods used can be explained in the following ways. (1) Different types and loads of indentation were used, and the reason behind this necessity has already been discussed. That said, both indentations did yield amorphization in both stoichiometries, as well as a reduced level of amorphization in the boron-rich sample. (2) With Raman spectroscopy, a volume is being probed with a laser, while with TEM, only a limited number of samples and regions can be similarly probed for comparison, so, in this regard, Raman is a more extensive method of gathering a larger amount of data on amorphization from an indent. Since Raman 
can probe a larger volume than a TEM image, there are more ways to explain the fact that a larger reduction was seen from this instrument: (a) the total volume of the plastically-deformed zone formed by the indent could be reduced from the boron-rich sample; (b) the amorphous bands could be smaller in size, mainly in length; or (c) there are fewer bands created by an indent. The Raman results could be a combination of all three scenarios $(a, b, c)$. The TEM image only shows a reduction from scenario (c), although scenario (a) and (b) are not disproved as further possibilities and contributions. Thus, between the differing methods, although slightly different in extent, a conclusion can be drawn that boron-rich boron carbide has less amorphization than nominal $B_{4} C$, something that can have a large influence on the material's performance and behavior in ballistic events.

\section{Conclusions}

Boron-rich boron carbide samples across the homogeneity range were prepared for this study, giving a $\mathrm{B} / \mathrm{C}$ ratio range from 4 to 6.5. Extensive Raman spectroscopy was done on indented regions to probe the stress-induced amorphous zones. Raman mapping the entirety of the $5 \mathrm{~N}$ Vickers indents, we see a $70 \%$ reduction in amorphization intensity for the boron-rich samples compared to $\mathrm{B}_{4} \mathrm{C}$. Additionally, the hardness of $\mathrm{B}_{4} \mathrm{C}$ was $34.6 \mathrm{GPa}$, and an approximate drop of $5 \%$ was observed for the more boron-rich samples, likely due to a lattice expansion from boron-doping.

Author Contributions: M.C.S.: Conceptualization, data collection, data analysis, writing, and editing. R.A.H.: Principal investigator, project administration, and funding acquisition. All authors have read and agreed to the published version of the manuscript.

Funding: Research was sponsored by the Army Research Laboratory and was accomplished under Cooperative Agreement Number W911NF-12-2-0022. Additional support was received from the National Science Foundation I/UCRC Award No.1540027. The views and conclusions contained in this document are those of the authors and should not be interpreted as representing the official policies, either expressed or implied, of the Army Research Laboratory, the National Science Foundation or the U.S. Government. The U.S. Government is authorized to reproduce and distribute reprints for Government purposes notwithstanding any copyright notation herein.

Acknowledgments: The authors would like to thank Tyler Munhollon for sample preparation, and Vlad Domnich for Raman spectroscopy insight.

Conflicts of Interest: The authors declare no conflicts of interest.

\section{References}

1. Domnich, V.; Reynaud, S.; Haber, R.A.; Chhowalla, M. Boron Carbide: Structure, Properties, and Stability under Stress. J. Am. Ceram. Soc. 2011, 94, 3605-3628. [CrossRef]

2. Thévenot, F. Boron carbide-A comprehensive review. J. Eur. Ceram. Soc. 1990, 6, 205-225. [CrossRef]

3. Tallant, D.R.; Aselage, T.L.; Campbell, A.N.; Emin, D. Boron carbide structure by Raman spectroscopy. Phys. Rev. B 1989, 40, 5649-5656. [CrossRef]

4. Fanchini, G.; McCauley, J.W.; Chhowalla, M. Behavior of Disordered Boron Carbide under Stress. Phys. Rev. Lett. 2006, 97, 035502. [CrossRef] [PubMed]

5. Grady, D.E. Shock-wave strength properties of boron carbide and silicon carbide. In Proceedings of the EURODYMAT '94: 1st International Conference on Mechanical and Physical Behavior of Materials under Dynamic Loading, Oxford, UK, 26-30 September 1994; Sandia National Labs.: Albuquerque, NM, USA, 1994; 4, pp. C8-385-C8-391.

6. Domnich, V.; Gogotsi, Y.; Trenary, M.; Tanaka, T. Nanoindentation and Raman spectroscopy studies of boron carbide single crystals. Appl. Phys. Lett. 2002, 81, 3783-3785. [CrossRef]

7. Chen, M.; McCauley, J.W.; Hemker, K.J. Shock-Induced Localized Amorphization in Boron Carbide. Science 2003, 299, 1563-1566. [CrossRef] [PubMed]

8. Ge, D.; Domnich, V.; Juliano, T.; Stach, E.A.; Gogotsi, Y. Structural damage in boron carbide under contact loading. Acta Mater. 2004, 52, 3921-3927. [CrossRef]

9. Reddy, K.M.; Liu, P.; Hirata, A.; Fujita, T.; Chen, M. Atomic structure of amorphous shear bands in boron carbide. Nature Commun. 2013, 4, 1-5. [CrossRef] 
10. Domnich, V.; Gogotsi, Y.; Trenary, M. Identification of Pressure-Induced Phase Transformations Using Nanoindentation. MRS Proc. 2000, 649, 8-9. [CrossRef]

11. Parsard, G.; Subhash, G. Raman spectroscopy mapping of amorphized zones beneath static and dynamic Vickers indentations on boron carbide. J. Eur. Ceram. Soc. 2017, 37, 1945-1953. [CrossRef]

12. Chen, M.; McCauley, J.W. Mechanical scratching induced phase transitions and reactions of boron carbide. J. Appl. Phys. 2006, 100, 123517. [CrossRef]

13. Chauhan, A.; Sun, X.; Ramesh, K.T.; Hemker, K.J. Dynamic failure mechanisms of granular boron carbide under multi-axial high-strain-rate loading. Scr. Mater. 2019, 173, 125-128. [CrossRef]

14. Fanchini, G.; Gupta, V.; Mann, A.B.; Chhowalla, M. In Situ Monitoring of Structural Changes in Boron Carbide Under Electric Fields. J. Am. Ceram. Soc. 2008, 91, 2666-2669. [CrossRef]

15. Zhao, S.; Kad, B.; Remington, B.A.; la Salvia, J.C.; Wehrenberg, C.E.; Behler, K.D.; Meyers, M.A. Directional amorphization of boron carbide subjected to laser shock compression. Proc. Natl. Acad. Sci. USA 2016, 113, 12088-12093. [CrossRef]

16. Gosset, D.; Miro, S.; Doriot, S.; Victor, G.; Motte, V. Evidence of amorphisation of B4C boron carbide under slow, heavy ion irradiation. Nucl. Instrum. Methods Phys. Res. Sec. B Beam Interact. Mater. Atoms 2015, 365, 300-304. [CrossRef]

17. Victor, G.; Pipon, Y.; Moncoffre, N.; Bérerd, N.; Esnouf, C.; Douillard, T.; Gentils, A. In situ TEM observations of ion irradiation damage in boron carbide. J. Eur. Ceram. Soc. 2019, 39, 726-734. [CrossRef]

18. Yan, X.Q.; Tang, Z.; Zhang, L.; Guo, J.J.; Jin, C.Q.; Zhang, Y.; Goto, T.; McCauley, J.W.; Chen, M.W. Depressurization amorphization of single-crystal boron carbide. Phys. Rev. Lett 2009, 102, 075505. [CrossRef]

19. Kunka, C.; Awasthi, A.; Subhash, G. Crystallographic and spectral equivalence of boron-carbide polymorphs. Scr. Mater. 2016, 122, 82-85. [CrossRef]

20. de Carlos, E.T.; James, W.M.; Wright, T.W. The effects of stoichiometry on the mechanical properties of icosahedral boron carbide under loading. J. Phys. Condens. Matter 2012, 24, 505402.

21. An, Q.; Goddard, W.A., 3rd; Cheng, T. Atomistic explanation of shear-induced amorphous band formation in boron carbide. Phys. Rev. Lett 2014, 113, 095501. [CrossRef]

22. An, Q.; Goddard, W.A. Microalloying Boron Carbide with Silicon to Achieve Dramatically Improved Ductility. J. Phys. Chem. Lett. 2014, 5, 4169-4174. [CrossRef]

23. An, Q.; Goddard, W.A. Boron Suboxide and Boron Subphosphide Crystals: Hard Ceram.s That Shear without Brittle Failure. Chem. Mat. 2015, 27, 2855-2860. [CrossRef]

24. Awasthi, A.P.; Subhash, G. High-pressure deformation and amorphization in boron carbide. J. Appl. Phys. 2019, 125, 215901. [CrossRef]

25. Jay, A.; Hardouin Duparc, O.; Sjakste, J.; Vast, N. Theoretical phase diagram of boron carbide from ambient to high pressure and temperature. J. Appl. Phys. 2019, 125, 185902. [CrossRef]

26. Aselage, T.L.; Tissot, R.G. Lattice Constants of Boron Carbides. J. Am. Ceram. Soc. 1992, 75, $2207-2212$. [CrossRef]

27. Yakel, H.L. The crystal structure of a boron-rich boron carbide. Acta Crystallogr. Sect. B Struct. Crystallogr. Cryst. Chem. 1975, 31, 1797-1806. [CrossRef]

28. Cheng, C.; Reddy, K.M.; Hirata, A.; Fujita, T.; Chen, M. Structure and mechanical properties of boron-rich boron carbides. J. Eur. Ceram. Soc. 2017, 37, 4514-4523. [CrossRef]

29. Xie, K.Y.; Domnich, V.; Farbaniec, L.; Chen, B.; Kuwelkar, K.; Ma, L.; McCauley, J.W.; Haber, R.A.; Ramesh, K.T.; Chen, M.; et al. Microstructural characterization of boron-rich boron carbide. Acta Mater. 2017, 136, $202-214$. [CrossRef]

30. Xie, K.Y.; An, Q.; Sato, T.; Breen, A.J.; Ringer, S.P.; Goddard, W.A., 3rd; Cairney, J.M.; Hemker, K.J. Breaking the icosahedra in boron carbide. Proc. Natl. Acad. Sci. USA 2016, 113, 12012-12016. [CrossRef]

31. Chauhan, A.; Schaefer, M.C.; Haber, R.A.; Hemker, K.J. Experimental observations of amorphization in stoichiometric and boron-rich boron carbide. Acta Mater. 2019, 181, 207-215. [CrossRef]

32. Munhollon, T.L. Chemical and Mechanical Analysis of Boron-Rich Boron Carbide Processed Via Spark Plasma Sintering. Ph.D. Thesis, Rutgers University of New Jersey, New Brunswick, NJ, USA, 2016.

33. Chandrashekhar, M.; Letton, J.; Williams, T.; Ajilore, A.; Spencer, M. Laser Induced Graphitization of Boron Carbide in Air. U.S. Patent 20190352234, 5 March 2019. 
34. Subhash, G.; Ghosh, D.; Blaber, J.; Zheng, J.Q.; Halls, V.; Masters, K. Characterization of the 3-D amorphized zone beneath a Vickers indentation in boron carbide using Raman spectroscopy. Acta Mater. 2013, 61, 3888-3896. [CrossRef]

35. Yang, Q.; Hwang, C.; Marvel, C.J.; Chauhan, A.; Domnich, V.; Khan, A.U.; la Salvia, J.C.; Harmer, M.P.; Hemker, K.J.; Haber, R.A. Fabrication and characterization of arc melted Si/B co-doped boron carbide. J. Eur. Ceram. Soc. 2019, 39, 5156-5166. [CrossRef]

36. Yang, Q.; Çelik, A.M.; Du, J.; la Salvia, J.C.; Hwang, C.; Haber, R.A. Advancing the mechanical properties of $\mathrm{Si} / \mathrm{B}$ co-doped boron carbide through $\mathrm{TiB}_{2}$ reinforcement. Mater. Lett. 2020, 266, 127480. [CrossRef]

37. Vast, N.; Lazzari, R.; Besson, J.M.; Baroni, S.; dal Corso, A. Atomic structure and vibrational properties of icosahedral $\alpha$-boron and B4C boron carbide. Comput. Mater. Sci. 2000, 17, 127-132. [CrossRef]

(C) 2020 by the authors. Licensee MDPI, Basel, Switzerland. This article is an open access article distributed under the terms and conditions of the Creative Commons Attribution (CC BY) license (http://creativecommons.org/licenses/by/4.0/). 